\title{
Causes and Outcome of Suicidal Cases Presented to a Medical Ward
}

\author{
S SHOAIB M A NADEEM MZU KHAN. \\ Department of Medicine, King Edward Medical College/Mayo Hospital, Lahore \\ Correspondence to Dr. Muhammad Arif Nadeem, Assistant Professor of Medicine
}

\begin{abstract}
Suicide is one of the leading causes of death in world but its causes and methods may vary. We enrolled patients who presented to the emergency with attempted suicide. The end point was death, discharge or leaving the hospital against medical advice. The study was designed to know the modes of committing suicide and underlying causes. Of the total 107 patients, who presented to the emergency $59(55 \%)$ were males and $48(45 \%)$ were females. Most common poison ingested was wheat pill in $35(33.3 \%)$ patients followed by bleach/bathroom cleaner in $27(25.7 \%)$, benzodiazepines in $20(19 \%)$ and a small proportion of patients had copper sulfate, organophosphorus compounds, rat pills, lice powder, dettol and varnish. Two patients presented after hanging. Twenty eight (26\%) patients died, just after reaching hospital and 10 had permanent disability. For suicide the most common poisons used were those that were easily available and without any ban on their sale. So general awareness should be created among masses about them and legal restrictions should be imposed on their sale.
\end{abstract}

Key words: Suicide, Wheat pill, Bleach/Bathroom cleaner, Benzodiazepines, Common.

Suicide is an act of taking one's own life voluntarily and intentionally ${ }^{1}$. Suicidal rate is high in societies that are socially isolated and disorganized. It is lower in countries or subcultures where religious or cultural norms prohibit the act of suicide ${ }^{2}$.

Different suicidal risk factors are present in different age groups. The teenager cannot compete with others, in young and middle aged adults there is lack of accomplishment of life goals along with failure in social relationships, while in elderly there is loss of friends and loved ones, health and financial problems and ideas of death $^{3}$.

Suicide is one of the ten leading causes of death in world, accounting for more than 400,000 deaths annually. The incidence and pattern of suicide vary from country to country. Cultural, religious and social values play some role in this regard. Suicide is more common in males than females and rates are said to increase with age ${ }^{5}$.

Suicide has been more prevalent in winter and spring. Very few studies about the epidemiology of suicide have been conducted in Pakistan and most are based on Newspaper reports ${ }^{6,7}$.

We chose to conduct this study in order to note the pattern of suicide presenting to a medical ward of Mayo Hospital, Lahore, and evaluate their outcome, and degree of mortality and morbidity associated with it. This is a step to recognize the risk and pattern of suicide. Different poisons which are commonly used to commit suicide are:

Wheat pill

This is a very dangerous poison freely available and is also very cheap. It contains Aluminum phosphide, which on contact to mucous membranes forms toxic phosphene gas that causes myocarditis immediately. Mortality is nearly $100 \%$. It has been observed in one of the recent study done at Mayo Hospital, Lahore that wheat pill poisoning is more common in females with $46.67 \%$ mortality $^{8}$. A higher mortality rate of $80 \%$ had been reported by Waseem et al. in $1997^{9}$.
Bleach poisoning/bathroom cleaner:

This is one of the common modes of poisoning, which is easily available in every house. The content of this are not usually mentioned on the bottle and is also sold freely and is again more common way of attempting suicide in females.

\section{Benzodiazepines}

They are also a common mode of poisoning but the lethal dose required is very high so people presenting after benzodiazepine poisoning have no permanent mortality or morbidity.

\section{Copper sulfate}

"Neela Thotha" is usual cause of exhibitional poisoning but sometimes it can cause renal or hepatic damage. In one of the local series, copper sulfate poisoning had $62.5 \%$ mortality ${ }^{8}$.

Rat pill

It contains a long acting warfarin like compound and can cause bleeding.

\section{Organophosphorus compounds}

These are insecticides, cause cholinergic symptoms and have almost $25 \%$ mortality $^{8}$.

There are many other different poisons, which have also been used for attempting suicide.

Patients and methods:

Between October 2003 to September 2004, 107 patients were enrolled who presented to the emergency of West Medical Ward and had ingested poison with suicidal intent. End point was leaving hospital either dead, discharged or against medical advice.

\section{Results:}

Of the total 107 patients who presented to the emergency, $59(55 \%)$ were males whereas female were $48(45 \%)$, (figure 1). Twenty eight (26\%) patients died and rest were saved (table 1). As for as age distribution is concerned they were divided according to the decades: 37 patients were in 
second decade of age i.e. 11-20 years, 52 patients in third decade (21-30 years), 11 patients in fourth decade (31-40 years), 3 in fifth one (41-50 years) and 4 in sixth decade (50-60 years), (figure 2). Out of them 10 patients were left with permanent disability i.e. 3 had permanent brain dysfunction, 6 had oesophageal strictures and 1 had abortion. Most common poison ingested was wheat pill in $35(33.3 \%)$ patients, which was the leading cause of death in 17 out of 28 patients. This was followed by bleach poisoning in $27(26 \%)$ patients and that was most common cause of morbidity. Anxiolytics were taken by 20 (19\%) patients, copper sulfate in $7.4 \%$, rat pill in $5.6 \%$ and rest of $8.4 \%$ patients took organophosphorus, lice powder, dettol, paracetamol, epival and varnish to attempt suicide. Two patients committed suicide by hanging. Ten patients were known to have psychiatric illness and had attempted it before as well.

Fig. 1: Sex Distribution of Patients attempting Suicide

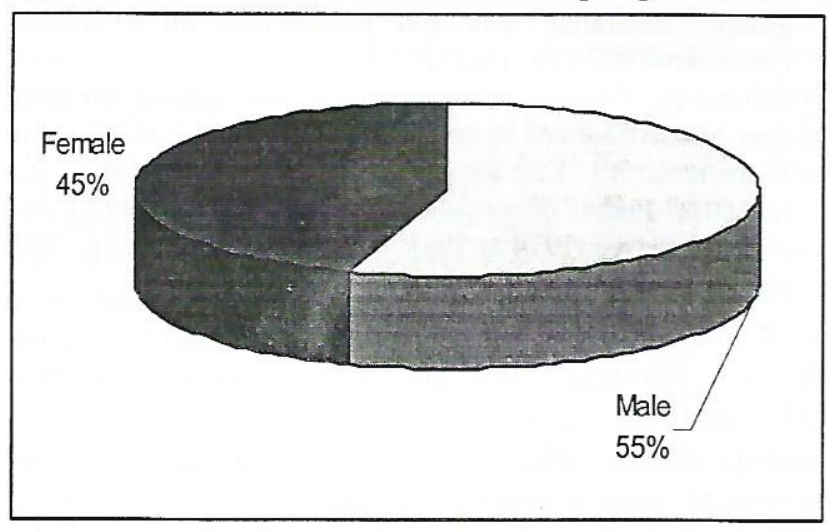

Fig. 2: Age Distribution of Patients attempting Suicide

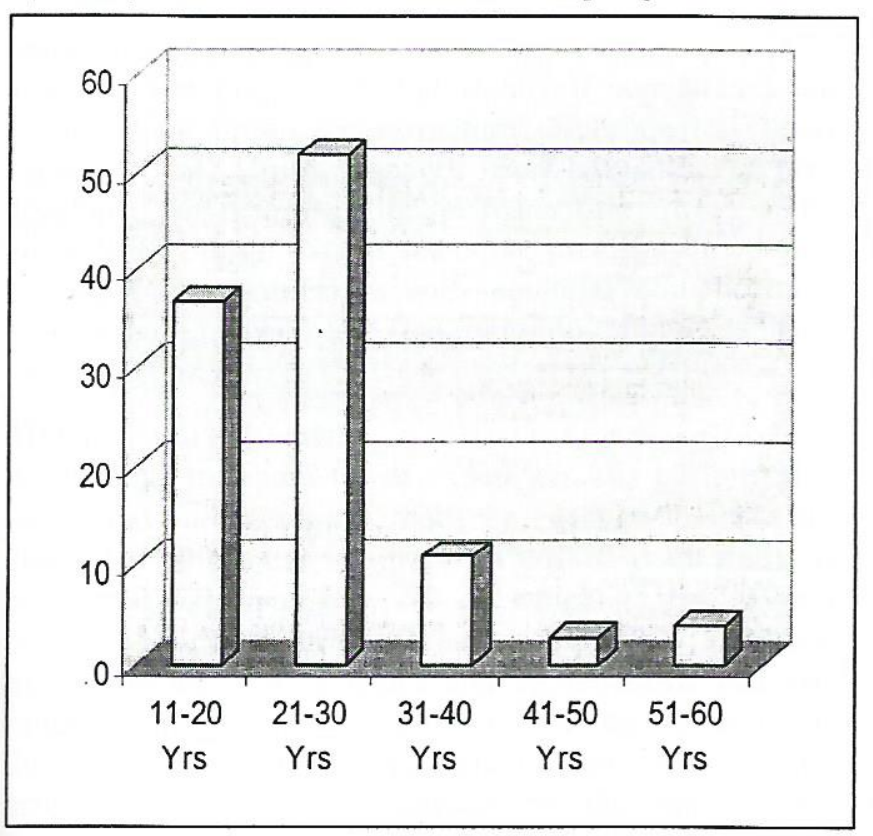

Table 1: Pattern of Poisons ingested for Suicide and its Fate

\begin{tabular}{lllll} 
Poison Ingested & $\mathrm{n}=$ & Mortality & Morbidity & Discharged \\
\hline Wheat pill & 35 & 23 & 00 & 12 \\
Bleach & 27 & 03 & 06 & 18 \\
Benzodiazepines & 20 & 00 & 00 & 20 \\
Copper sulfate & 08 & 00 & 00 & 06 \\
Rat pill & 06 & 00 & 01 & 00 \\
Tab. Daonil & 01 & 00 & 00 & 00 \\
Varnish & 01 & 01 & 00 & 00 \\
Lice powder & 03 & 01 & 01 & 01 \\
Others & 06 & 00 & 00 & 01 \\
\hline
\end{tabular}

\section{Discussion:}

Suicide is a leading cause of death in the world. However, incidence and pattern of suicide varies from country to country depending upon social, cultural and religious values ${ }^{4}$. The rate of suicide in our country is less than USA, UK, Switzerland and China, whereas it is nearer to that of Jordan and Nigeria ${ }^{10,}{ }^{11}$. One reason for this difference may be the degree of urbanization and industrial development in developed countries that has resulted in increasing detachment of individual's identification with social group that controls and defines this action. Yet another important reason could be the role of religion specially the belief in the world hereafter, which prevents the feeling of hopelessness, a feeling that has been described as important predisposing factor for suicide ${ }^{2}$. In addition religious codes of Islam strictly prohibit suicide ${ }^{1}$. The gender ratio in our study is similar to accepted view of male dominance that has also been reported in many other countries as well as in other local study ${ }^{12,13}$. About $80 \%$ of patients were between $10-29$ years, and $20 \%$ between 30 60 years. Only 4 patients above 50 had attempted suicide. This finding goes against the increasing incidence of suicide with age $^{14}$. The causes, for which the patient commit suicide in younger age group, are usually love affairs that are unsuccessful either due to other partner or the family, inability to find job and failure in examinations whereas in fourth decade, this is usually fight with spouse or financial problems whereas in old age usually due to children ignoring their parents. Females usually commit suicide with bleach, which usually do not result in mortality but can cause long term morbidity by causing oesophageal strictures and much difficult long term problem. These are very easily available and usually no contents are mentioned on the bottle. Wheat pill a deadly poison causes high mortality ${ }^{8,9}$ and patients who are saved 
from it either have a doubtful history of its intake or have taken long kept pills that are less toxic. These pills are very cheap and freely available. Many patients by attempting to commit suicide want to gain sympathies and do not want to die like those taking copper sulfate, anxiolytics, dettol etc.

Therefore, from this study it can be concluded that patients, presented to the emergency of West Medical Ward Mayo Hospital, Lahore, a tertiary care hospital, who have poisoned themselves deliberately in order to die, use easily available toxic substances that cause major mortality and morbidity. The sale of such drugs and poisons should be restricted and general awareness should be created among masses about them.

\section{References:}

1. Awan NR. Principles and practice of Forensic Medicine. Lahore: Sublime Arts; 2002:25.

2. Bluglass $R$, Bawden $P$ eds. Principles and practice of Forensic Psychiatry. Edinburgh: Churchill Living stone; 1990:213-606.

3. Curran WJ, McGarry AL, Petty CS. Modern Legal Medicine, Psychiatry and Forensic Science. Philadelphia: F.A. Davis Company; 1980: 172-850.

4. Nadesan K. Pattern of suicide: a review of autopsies conducted at University Hospital, Kuala Lumpur. Malays J Pathol 1999 Dec; 21(2): 95-9.
5. S. Hatcher S. Debt and deliberate self poisoning. Brit J Psychiatry. 1994; 164, 111-4.

6. Khan MM, Reza H. The pattern of suicide in Pakistan Crisis 2000; 21(1):31-5.

7. Khalid N. Pattern of suicide: causes and method employed. J Call Physician Surg Park Dec 2001; 11(12): 759-61.

8. Waseem $T$, Nadeem M A, Irfan $K$, Waheed $K$ A I. Poisonings in Patients of Medical Coma and their Outcome at Mayo Hospital, Lahore. Annals of King Edward Medical College, Lahore 2004; 10 (4): 384-386.

9. Waseem T, Bhatti N B, Khan A H, Nasir N. Acute poisoning due to wheat preservative aluminum phosphide. Pak J Cardiol 1997; 8 (3-4): 43-48.

10. Miran Canelo JA, Saenz Gonzalez MC, Blanco Montagut. L, Fernandez Martin C. Descriptive epidemiology of suicide in Spain (1906-1990) Actas Luso Esp Neural Psiquiatar Cienc Afines 1997 Sept.-Oct; 25(5): 327-31.

11. Daly C, Kelleher MJ, Crowley MJ, Daly M, Keohane B, Daly F, McLeavey BC. Suicide levels in Cork City 1987/1991. Ir Med J 1996 May-Jun; 89(3); 99-101.

12. Snowdon J. Suicide rates and methods-in different age groups: Australian data and perceptions. Int $\mathrm{J}$ Geriatr Psychiatry $1997 \mathrm{Feb} ; 12(2): 253-8$.

13. Sultana K. Proportion of suicidal deaths among autopsy. Ann Abbasi Shaheed Hosp Karachi Mar 2002; 7:317-8.

14. Yamamoto $\mathrm{Y}$, Yamada $\mathrm{M}$, Fukunaga $\mathrm{T}$, Tatsuno $\mathrm{Y}$. Statistical studies on suicides in Shiga Prefecture during the 15-years period, 1974 to 1988. Nippon Hoigaku Zasshi 1990 Apr; 44(2):190-8. 